\title{
A prática do basquetebol por meninas nas aulas de educação fí- sica escolar no município de Volta Redonda: a visão dos profes- sores
}

\author{
The basketball practice for girls in school physical education in Volta Re- \\ donda: the the view of teachers
}

Claudio Delunardo Severino ${ }^{*}$, Francisco José Miranda Gonçalves ${ }^{2}$, Suraya Cristina Dari$\mathrm{do}^{3}$

ARTIGO ORIGINAL |ORIGINAL ARTICLE

\begin{abstract}
A presente pesquisa teve como objetivo geral abordar a participação feminina nas aulas de Educação Física, com enfoque no Basquetebol como conteúdo. Participaram da pesquisa professores das instituições públicas e privadas do município de Volta Redonda/RJ/Brasil em turmas do $6^{\circ}$ ao $9^{\circ}$ ano do Ensino Fundamental. Tratou-se de um estudo quanti-qualitativo com análise de conteúdo e, como procedimento de coleta de dados, foram entrevistados sessenta docentes que opinaram acerca da questão investigada. Verificou-se que a realidade da Educação Física no município de Volta Redonda apresenta, de maneira geral, características de um modelo baseado no ensino dos esportes de acordo com as concepções subordinadas ao alto rendimento. Considera-se também que a Educação Física pode ser vista como uma aliada importante no alcance de objetivos vinculados à formação de valores e a prática do Basquetebol em ambiente escolar por meninas pode representar um novo desenho quanto a compreensão de igualdade de direitos e não hierarquização por parte dos discentes.
\end{abstract}

Palavras-chaves: Basquetebol, Educação Física, Escola, Meninas

$\begin{array}{ll}\text { ABSTRACT } & \end{array}$

This research aims to address girls participation in Physical Education classes, with a focus on Basketball as content. Teachers participated in the survey of public and private institutions in the city of Volta Redonda / RJ / Brazil in classes from 6th to 9th grade of elementary school. This was a quantitative and qualitative study of content analysis and as a data collection procedure, sixty teachers who opined on the issue investigated were interviewed. It was found that the reality of Physical Education in Volta Redonda has, in general, characteristics of a model based on the teaching of sports according to the conceptions subordinated high yield. It is also considered that Physical Education can be seen as an important ally in reaching goals linked to the formation of values, practicing Basketball in a school environment for girls may represent a new drawing and understanding of equal rights and not by hierarchy among learners.

Keywords: Basketball, Physical Education, School, Girls

Artigo recebido a02.02.2014; Aceitea 25.06.2014

${ }^{1}$ Centro Universitário de Volta Redonda - UniFOA, Rio de Janeiro, Brasil

${ }^{2}$ Instituto Superior da Maia, Maia, Portugal

${ }^{3}$ Instituto de Biociências, Departamento de Educação Física, Universidade Estadual Paulista, UNESP, São Paulo, Brasil

* Autor correspondente: Centro Universitário de Volta Redonda - UniFOA. Avenida Paulo Erlei Alves Abrantes, 1325, Três Poços, Volta Redonda, Rio de Janeiro - Brasil. CEP 27240-560

E-mail: claudiodelunardo@gmail.com 


\section{INTRODUÇÃO}

O Esporte é muitas vezes é visto como um significativo fenômeno sociocultural, mesmo que, no plano histórico, a sociedade nem sempre o tenha considerado como um ambiente democrático. Isso se deve ao fato de que a prevalência dos atributos considerados como exclusivamente masculinos ocasionavam uma prática elitista, outrora incompatível com a fragilidade e a delicadeza, características atribuídas às mulheres (Cruz \& Palmeira, 2009). Percebe-se o espaço escolar comum como o ambiente adequado para a utilização do Esporte, reconhecendo-se a sua importância para o desenvolvimento global dos alunos. Todavia, nota-se que a sua introdução como conteúdo das aulas de Educação Física não garantiu uma alteração do pensamento voltado para a prática esportiva elitista que ainda percebe nas mulheres um corpo frágil que não resiste aos impactos causados pela atividade física (Cruz \& Palmeira, 2009; H. A. Rodrigues \& Darido, 2012).

A destacar o cenário das aulas de Educação Física em ambiente escolar, conforme Bassani, Torri, e Vaz (2007), a segregação entre meninas e meninos sustenta-se principalmente no discurso de que as discentes representam o paradigma de inferioridade esportiva. Para Fotrousi, Bagherly, e Ghasemi (2012), as diferenças relacionadas ao gênero fundamentamse, além dos ambientes sociais e físicos, em situações criadas no decorrer das aulas de Educação Física.

Na perspetiva de Daólio (1995), a caracterização de formas de preconceito não pode servir para considerar que todas as meninas são desprovidas de habilidade para a prática esportiva, aqui em se tratando particularmente do Basquetebol. Da mesma forma, o autor observou que nem todos os meninos podem ser considerados hábeis e, portanto, faz-se necessário que o professor responsável por direcionar as atividades perceba que as diferenças de caráter motor não são determinadas biologicamente, mas construídas pela cultura na qual o contexto está inserido. Esse contexto tem sido muitas vezes influenciado pelo discurso de que, hie- rarquicamente, existe o domínio de um sexo pelo outro.

Rodrigues e Darido (2011) consideram que as meninas que se propõem jogar Basquetebol enfrentam, além das próprias dificuldades inerentes da modalidade, o preconceito. Pelo fato de ser o Basquetebol uma modalidade muito praticada pelos homens, os autores observam que isso faz com que se estabeleça uma impressão errônea de que se trata de uma prática exclusivamente masculina, fazendo com que as meninas basquetebolistas sofram críticas inclusive quanto à orientação sexual.

O presente estudo justifica-se, além da sua importância como produção de conhecimentos voltados para a área da Educação Física Escolar, pela relevância acerca da sua contribuição ao desenvolvimento global dos discentes. Para Knijnik (2010), a questão do gênero aponta para o fato de que, por intermédio de inúmeras práticas sociais, a sociedade se constitui baseada na distinção entre homens e mulheres num processo que não pode ser considerado harmônico ou linear. O mesmo autor observa ainda que o conceito de gênero propõe um afastamento das análises que envolvem uma noção diminuta dos papéis do homem e da mulher. Neste caso, há uma abordagem que considera as instituições sociais, normas, leis e doutrinas que são constituídas por representações de masculino e feminino relacionadas à produção e manutenção de uma ordem preestabelecida.

Nessa perspetiva, torna-se relevante compreender a realidade em que se encontra a Educação Física Escolar no município de Volta Redonda com aproximadamente 275.000 habitantes e localizado a $124 \mathrm{~km}$ da cidade do Rio de Janeiro e a $318 \mathrm{~km}$ da cidade de São Paulo, duas das principais cidades do Brasil. Diante disto, o presente estudo teve como objetivo investigar a participação feminina nas aulas de Educação Física no referido município, a considerar o Basquetebol como conteúdo e a partir da visão dos professores. Trata-se de um estudo quanti-qualitativo no qual se almeja a compreensão da realidade e ser investigada, bem 
como a sua interpretação (J. V. P. Silva, Dagostin, \& Nunez, 2009).

\section{MÉTODO}

\section{Participantes}

Participaram da pesquisa licenciados em Educação Física, efetivos dos quadros docentes das instituições de ensino no município de Volta Redonda - RJ e que lecionam nas turmas de $6^{\circ}$ ao $9^{\circ}$ ano do Ensino Fundamental. O número de sujeitos participantes foi de 60 professores de Educação Física de ambos os sexos, o que representa $46.87 \%$ dos docentes que atuam nas escolas com Ensino Fundamental situadas em Volta Redonda, no segundo segmento do Ensino Fundamental. Para determinação do percentual de participantes da pesquisa, considerou-se o referido índice utilizado em outros estudos, a saber, Betti e Liz (2003), 30\%; Newland, Newton, Finch, Harbke, e Podlog (2013), 37\%; Shen (2014), 30.27\%.

Salienta-se que os participantes da pesquisa cumpriram com todos os procedimentos necessários de acordo com o Comitê de Pesquisas em Seres Humanos do Centro Universitário de Volta Redonda - UniFOA, o qual foi submetido o projeto e aprovado sob o Parecer Consubstanciado $n^{\circ} .211 .669$ e Certificado de Apresentação para Apreciação Ética n. ${ }^{\circ}$ 02350612.7.0000.5237.

\section{Instrumentos}

Como instrumento de coleta de dados, utilizou-se uma entrevista semiestruturada, gravada e transcrita contendo duas perguntas: a) Caso desenvolva o Basquetebol como conteúdo das aulas, você nota diferenças em trabalhar este conteúdo com meninas e, havendo essa perceção, quais seriam as diferenças? b) Você considera que há diferenças de rendimento de aprendizagem entre meninas e meninos nas aulas de Educação Física? Além da entrevista, com o intuito de estabelecer uma identificação mais apurada da amostra, utilizou-se uma ficha contendo questões associadas ao campo de ação e características que envolvem o histórico esportivo, acadêmico e profissional dos docentes entrevistados.

A entrevista semiestruturada possibilita a coleta de informações sem respostas completas e com o controle por parte do pesquisador, pois as questões a serem investigadas são previamente estabelecidas pelo mesmo (Ferreira \& Moraes, 2012; Thomas, Nelson, \& Silverman, 2012).

A construção do instrumento de coleta de dados baseou-se nas categorias empíricas construídas a partir da revisão bibliográfica relacionada aos processos metodológicos de avaliação. A partir da designação de algumas questões prioritárias que passaram por um processo de análise e seleção no qual algumas foram refeitas ou excluídas, as categorias organizadas foram: o Basquetebol como conteúdo das aulas e o desenvolvimento motor e cognitivo das meninas em relação aos objetivos vinculados ao processo de ensino e aprendizagem do Basquetebol.

Para a validação do instrumento de coleta de dados, obedeceu-se a dois procedimentos. No primeiro momento, o instrumento foi validado qualitativamente por 5 professores doutores com conhecimento reconhecido sobre a área de estudo e com experiência voltada para a validação de instrumentos de coleta de dados, que sugeriram e orientaram modificações no sentido de tornar o guia de entrevista mais objetivo e coerente com o objetivo do estudo. Após esse procedimento e para testar a confiabilidade do instrumento, o mesmo foi submetido a um teste-piloto, no qual foi aplicado junto a oito professores de Educação Física (13.33\% dos participantes da pesquisa) com conhecimento notório e experiência com o Basquetebol em ambiente escolar. Posteriormente, foi solicitado aos professores que apresentassem informações e sugestões no que tange ao grau de compreensão das perguntas, tempo de aplicação da entrevista e acréscimo ou retirada de questões. Esta solicitação teve como principal objetivo a apuração da qualidade do instrumento, bem como a perceção de 
uma possível adequação do procedimento de coleta de dados.

\section{Procedimentos}

Com o intuito de garantir um maior controle do procedimento de coleta de dados, o instrumento obedeceu as seguintes etapas (Santos, 2011): levantamento bibliográfico; organização das categorias empíricas; planejamento do roteiro da entrevista; validação dos instrumentos por peritos; pré-testagem do instrumento, que envolveu a aplicação no públicopiloto, validação e estimativa de resultados; seleção dos entrevistados; agendamento das entrevistas; cronograma de execução; registro das respostas por meio de gravações; apuração dos dados colhidos; transcrição e organização dos dados.

Foram registradas entrevistas áudiogravadas com 39 professores do sexo masculino e 21 do sexo feminino, sendo que a duração média das entrevistas foi de 8 minutos. Após a realização das entrevistas, os dados coletados foram transcritos por intermédio de digitação para posterior análise (Ferreira \& Moraes, 2012). A considerar que o gravador dá a oportunidade de coletar as respostas dadas pelos participantes sem que se perca qualquer dado para a realização das entrevistas, o equipamento utilizado foi um aparelho digital Sony ICD-PX312F 2GB.

Utilizou-se a coleta direta de dados de forma ocasional para que se pudesse dar conta do recorte espacial a ser pesquisado. Para a coleta de dados foi necessário o preenchimento do termo livre esclarecido de concessão de direitos, a assinatura da carta de anuência e a concessão da entrevista.

Com base nos estudos realizados por Sáiz, Calvo, e Godoy (2009) e Brown e Macdonald (2011), após a transcrição das entrevistas, uma cópia foi entregue a cada professor entrevistado, assim como o resumo da interpretação realizado pelo pesquisador. Esse procedimento teve como objetivo apresentar aos professores a possibilidade de verificação de suas opiniões bem como a veracidade das interpretações com vista a analisar a validade interna de constructo. É importante observar que segundo o estudo de Sáizet al. (2009), o monitoramento realizado pelos sujeitos da pesquisa representa a melhor maneira de garantir a credibilidade da pesquisa.

\section{Análise dos dados}

Por meio das transcrições, os dados colhidos nas entrevistas foram submetidos a uma análise de conteúdo pelo programa NVIVO 10, software especificamente projetado para analisar os dados qualitativamente, realizando-se posteriormente uma análise interpretativa dos resultados a partir do referencial teórico utilizado, com o intuito de se obter as percentagens de ocorrência. Baseando-se no procedimento apresentado por Boyle, Jones, e Walters (2008) em seus estudos, foram utilizados no processo de análise de conteúdo as seguintes etapas: a)após serem transcritos para um arquivo de texto, os dados foram lidos e organizados; b) os dados coletados foram devidamente codificados em categorias previamente identificadas de acordo com os temas vinculados aos docentes entrevistados.

Conforme mencionado anteriormente, o presente estudo baseou-se em categorias empíricas. Essas categorias apresentam como componente principal o objeto de estudo, o que, para Souza Júnior, Melo, e Santiago (2010), torna-se relevante a análise destas em função da sua apresentação sobre o que se deseja investigar, bem como se expressarão. As categorias foram ramificadas conforme o exposto na figura 1.

Observa-se que, de acordo com Minayo (2010), as categorias empíricas foram escolhidas a partir de sua finalidade operacional, partindo da premissa de que elas possuíam características que as possibilitavam emergir de e no processo de análise. Diante disso, relevou-se a possibilidade de, após o diálogo entre o referencial teórico e os dados obtidos, estabelecerse a compreensão acerca do tema a ser investigado. 


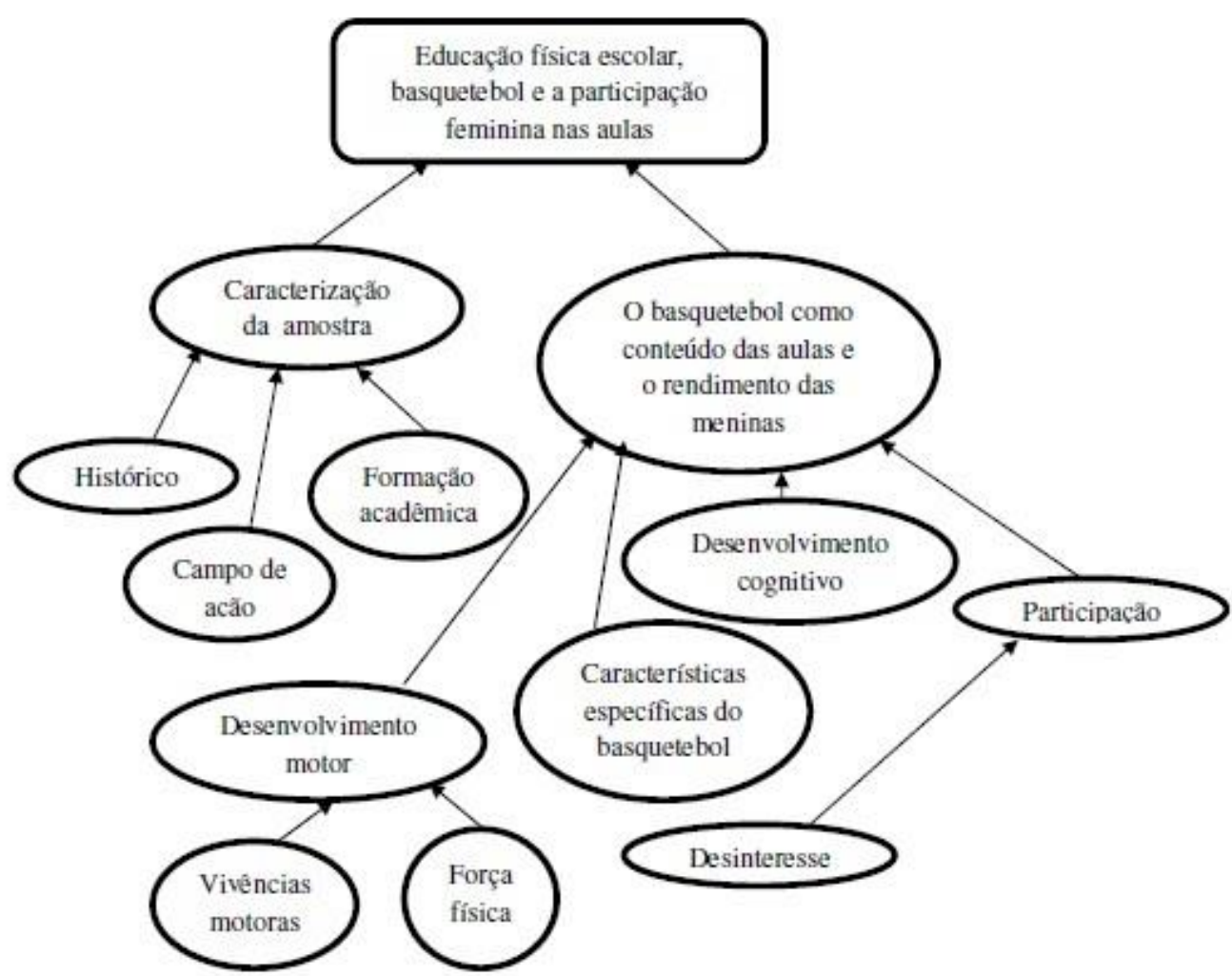

Figura 1. Modelo de identificação das categorias analíticas para conhecimento do objeto de estudo.

\section{RESULTADOS}

Descreve-se inicialmente o campo de ação dos docentes participantes da pesquisa, a considerar as redes pública e privada de ensino (figura 2). Observa-se também que alguns docentes participantes da pesquisa lecionam em ambas as redes.

As características que envolvem o histórico esportivo, acadêmico e profissional dos docentes entrevistados estão descritas na tabela 1 , a considerar o contato com o Basquetebol como experiência esportiva, a relação dos docentes com a modalidade na qualidade de ex-atletas e a participação em jogos e competições.

Acerca da qualificação dos docentes entrevistados, houve uma incidência maior de especialistas (lato sensu) em relação ao percentual de graduados e mestres (strictosensu), conforme tabela 2 .

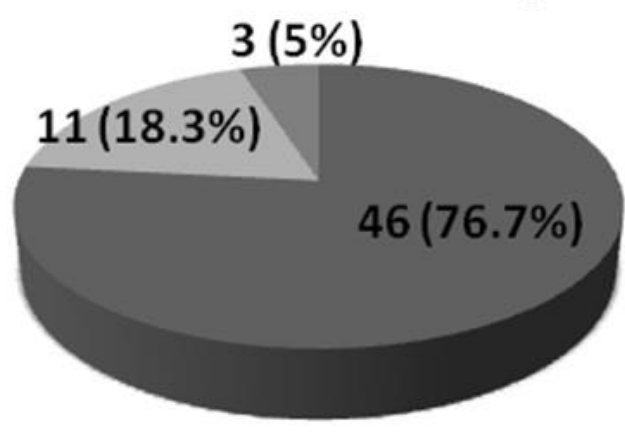

Rede Pública

Rede Privada

Ambas

Figura 2. Campos de ação dos docentes entrevistados 
Tabela 1

Histórico esportivo, acadêmico e profissional dos docentes entrevistados

\begin{tabular}{lc}
\hline HISTÓRICO ESPORTIVO & FREQUÊNCIA \\
Atletas de Basquetebol & 01 \\
Atletas de outras modalidades esportivas & 03 \\
Ex-atletas de Basquetebol & 07 \\
Ex-atletas de outras modalidades esportivas & 37 \\
\hline HISTÓRICO ACADÊMICO & FREQUÊNCIA \\
\hline Graduados entre 0 e 5 anos & 07 \\
Graduados entre 6 e 10 anos & 12 \\
Graduados entre 11 e 15 anos & 04 \\
Graduados entre 16 e 20 anos & 11 \\
Graduados entre 21 e 30 anos & 18 \\
Graduados entre 31 anos ou mais & 06 \\
\hline HISTÓRICO PROFISSIONAL & FREQUÊNCIA \\
\hline Professor de EF Escolar entre 0 e 5 anos & 18 \\
Professor de EF Escolar entre 6 e 10 anos & 10 \\
Professor de EF Escolar entre 11 e 15 anos & 04 \\
Professor de EF Escolar entre 16 e 20 anos & 10 \\
Professor de EF Escolar entre 21 e 30 anos & 15 \\
Professor de EF Escolar entre 31 anos ou mais & 02 \\
\hline
\end{tabular}

Além da caracterização da amostra, analisou-se posteriormente outras três categorias associadas ao objetivo do presente estudo. Os resultados com a incidência das respostas relacionadas às mesmas são apresentadas na tabela 3.

Tabela 3

Incidências das respostas apresentadas
Tabela 2

Titulação dos docentes entrevistados

\begin{tabular}{lcc}
\hline & N. $^{\circ}$ Docentes & \% \\
\hline Graduados & 23 & 38.3 \\
Especialistas (lato sensu) & 29 & 48.4 \\
Mestres (strictosensu) & 08 & 13.3 \\
\hline
\end{tabular}

Relação do Basquetebol como conteúdo das aulas de Educação Física e o rendimento das meninas

Diferença de rendimento entre ambos (49)

Igualdade de rendimento entre ambos (11)

Características específicas do basquetebol (5)

Desenvolvimento motor (24)

Vivências motoras (15)

Força física (6)

Desinteresse (10)

Desenvolvimento cognitivo (18)

Participação (5)

Vergonha (5)

Medo (1)

Vaidade (4)

Percebeu-se a predominância das respostas dos participantes que apontam a diferença de rendimento entre meninos e meninas no desenvolvimento do conteúdo Basquetebol, a considerar os professores entrevistados que apresentaram essa perceção em relação aos que afirmaram não haver qualquer tipo de distinção no que tange ao desempenho dos discentes nas aulas de Educação Física, independente do gênero.

Como possíveis causas que possam justificar a predominância mencionada, alguns fato- res foram apontados. A causa de maior incidência está relacionada ao desenvolvimento motor, onde se indicou que a carência de habilidades por parte das meninas representa uma dificuldade quanto ao processo de ensino e aprendizagem do Basquetebol. Ainda sobre a questão do desenvolvimento motor, mencionou-se a ausência de vivências motoras como responsável pela pouca prática de habilidades por parte das meninas, além da força física. 
A diferença que eu acho é que os meninos são mais habilidosos, mais fortes e isso acaba auxiliando na hora do jogo. Creio que isso acontece porque os meninos já vêm com uma vivência de brincadeiras e outras atividades ( $P$. 44).

Houve a menção do desenvolvimento cognitivo como causa das diferenças de desempenho entre discentes do sexo masculino e feminino. Ressalta-se que, acerca desse tópico, ocorreram citações que apontam um rendimento favorável às meninas.

Quando você se propõe a avaliar o aprendizado, as meninas apresentam um desempenho motor até melhor do que os meninos (P. 25).

Algumas características específicas do Basquetebol foram citadas como empecilho para o desenvolvimento de movimentos fundamentais pelas meninas, entre elas, a altura do aro em relação ao solo e o tamanho e peso da bola.

A estatura do aluno influencia a habilidade com a bola, enfim. Então, as garotas que têm uma estatura menor sentem dificuldade para jogar Basquetebol com os garotos. Sem contar o peso da bola, a altura da tabela, características do jogo que dificultam a participação das meninas (P. 4).

A participação das meninas das aulas de Educação Física foi abordada em algumas respostas concedidas pelos professores. O visível desinteresse por parte das discentes em relação às atividades propostas foi mencionada, além da rara participação e comprometimento das meninas em relação aos objetivos propostos.

A garota já chega à escola, quando falam que tem que fazer Educação Física, já não gostam. Inventam desculpas e muitas vezes nem fazem a aula (P. 31).
Particularidades vinculadas aos sentimentos das discentes foram verificadas. A vergonha, a vaidade e o medo por parte das meninas, segundo os entrevistados, influem no rendimento das meninas no Basquetebol como conteúdo das aulas de Educação Física em ambiente escolar.

A maioria acaba se privando porque tem vergonha do grupo, por questôes estéticas e porque não gostam mesmo. Isso prejudica a aprendizagem delas (P. 14).

\section{DISCUSSÃO}

O presente estudo pretendeu investigar a participação feminina nas aulas de Educação Física no município de Volta Redonda, a se considerar o Basquetebol como conteúdo e a partir da visão dos professores.

Os resultados demonstram que ainda é possível notar, segundo os docentes entrevistados, uma nítida distinção de rendimento entre meninas e meninos em se tratando do Basquetebol como conteúdo das aulas de Educação Física.

Normalmente eu noto uma facilidade de assimilação maior por parte dos meninos (P. 6).

Eles conseguem aprender mais rápido o jogo, entendem mais rápido a dinâmica do jogo e se empenham mais durante a aula ( $P$. 29).

$\mathrm{O}$ rendimento mencionado pelos docentes entrevistados é o resultado obtido pela realização de gestos específicos regulamentados de acordo com os padrões preestabelecidos. Dessa forma, há a preocupação com o aprendizado formal do Basquetebol, sem a intencionalidade educacional e a preocupação com a formação integral dos discentes (Abreu, 1995; Cairney et al., 2012; Kunz, 2006).

Entre as causas mais frequentes apontadas pelos professores entrevistados que possam vir a justificar a diferença de rendimento entre meninos e meninas está a prevalência de difi- 
culdades motoras por parte das discentes, apontada por 21 (35\%) docentes entrevistados. Expressões como "deficiência motora", "falta de vivência motora" e "repertório motor menor" são algumas das utilizadas pelos professores para justificar as dificuldades apresentadas pelas meninas quanto ao aprendizado formal do Basquetebol. Para Abreu (1995), essa realidade deve-se à falta de prática decorrente de questões culturais, como por exemplo, brincadeiras infantis características das meninas e ausência da participação da família no que tange ao incentivo à uma vida mais ativa. Essa observação se relaciona a outro dado exposto nas entrevistas realizadas, que se refere à prática esportiva na infância.

Alguns meninos carregam um repertório motor maior pela própria vivência deles de brincarem na rua desde cedo. Desde pequenos os meninos estão acostumados a praticar todos os esportes (P. 35).

Os estudos de Silva, Matias, Viana, e Andrade (2012) verificaram que as meninas se envolvem menos com a prática de exercícios físicos em geral, muito em decorrência de uma menor motivação intrínseca e autodeterminação em relação aos meninos. Slater e Tiggemann (2011) observaram que a diminuição da participação esportiva por parte das meninas também podem estar associadas a outras razões, como as diferenças na disponibilidade de opções esportivas, desmotivação e expectativas de papéis de gênero. $\mathrm{Na}$ mesma perspectiva, Vilhjalmsson e Kristjansdottir (2003) e Klomsten, Marsh, e Skaalvik (2005) apontam que os professores de Educação Física e os pais influenciam mais os meninos do que as meninas quanto à prática esportiva.

A função cognitiva foi apresentada com relativa incidência nas entrevistas, mesmo que não tenha sido mencionada por nenhum dos participantes da pesquisa a aplicação de testes que pudessem apurar o nível de cognição dos alunos. Entretanto, quanto às menções ocorridas, houve predominância entre os professores
(85.71\%) que apontaram um desempenho cognitivo favorável às meninas e os que fizeram o mesmo em relação aos meninos.

Agora, a parte cognitiva, na hora de compreender determinadas situaçôes, as meninas se saem melhor! (P. 40).

Se na parte prática os meninos se destacam mais, na sala de aula as meninas apresentam um melhor entendimento quanto aos conteúdos trabalhados (P. 51).

Dificuldades de aprendizagem podem estar vinculadas a questões como a condição econômica, problemas emocionais e nutrição inadequada, entre outras. Meninas, com dificuldades de aprendizagem ou não, não apresentam distinções acerca da execução de movimentos, podendo essa complicação ser relacionada à ausência de estímulos (Abreu, 1995; Daólio, 1995; Silva \& Beltrame, 2011; Klomsten, Marsh, \& Skaalvik, 2005; Vilhjalmsson \& Kristjansdottir, 2003). Todavia, os testes realizados Wu, Pender, e Noureddine (2003) indicam que não há diferenças cognitivas correlacionadas com a distinção de gêneros. Meninas, com dificuldades de aprendizagem ou não, não apresentam distinções acerca da execução de movimentos.

Ao analisar as opiniões dos professores ainda a respeito do rendimento das meninas, verificou-se menções vinculadas à pouca participação e ao desinteresse das discentes pelas atividades voltadas para a prática do Basquetebol.

Eu acredito que há diferença de rendimento e para mim o principal motivo para haver essa diferença é porque os meninos demonstram muito mais interesse em realizar a aula do que as meninas, esse é o principal motivo. Parece que elas não gostam das aulas práticas (P. 8).

Uma possível falta de participação das aulas de Educação Física por parte de meninas quando são desenvolvidos conteúdos relacionados ao Esporte, tendo o Basquetebol como referên- 
cia no presente estudo, não pode ser interpretado como um processo ocasionado por uma mera desmotivação pois, de acordo com Balbinotti, Saldanha, e Balbinotti (2009), não se apresentam distinções relevantes nos índices de motivação relacionados à prática de alguma modalidade esportiva, por parte de ambos os sexos. Há ainda a exposição feita por Duarte e Mourão (2007), que para a obtenção do êxito nas aulas de Educação Física, muitas vezes é necessária a execução de movimentos de acordo com técnicas específicas, repetições de exercícios e disputas, o que pode ser considerado como um conjunto de causas que levam as meninas a se considerarem frágeis e inaptas para participarem das aulas.

A altura do aro em relação ao solo e o tamanho e peso da bola foram citados como fatores que influenciam o rendimento das alunas. Para os docentes participantes do estudo que fizeram essa menção, a bola é muito pesada para uma menina arremessá-la em um alvo colocado a uma altura tão grande.

$A$ altura do aro é a mesma para ambos, o peso da bola também. Então é provável que o gesto de um arremesso feito por uma menina seja com as duas mãos porque ele nem sempre tem força suficiente para fazer isso, pois a bola parece pesada para a menina ( $P$. 2).

O professor, ao planejar a sua aula, deve ter a preocupação criteriosa a respeito dos materiais a serem utilizados e do espaço disponível para a realização das atividades. Rodrigues e Darido (2012), ao discutirem as aulas de Basquetebol, propõem uma diversificação dos espaços e materiais com o intuito de motivar a todos os alunos, e não apenas aos mais habilidosos. Para os autores, as aulas não podem ser alicerçadas apenas em materiais esportivos e quadras com dimensões ao menos próximas às oficiais, mas que, por intermédio de procedimentos didáticos, haja uma flexibilização em relação a utilização de materiais alternativos e instalações que ofereçam oportunidade de participação de todos os alunos.

De acordo com os depoimentos dos professores entrevistados, questões vinculadas a sentimentos foram apontadas, como a timidez, a vergonha e a vaidade.

A maioria das meninas acaba não fazendo aula porque tem vergonha do grupo, por questôes estéticas ou porque acham que não conseguem fazer nada mesmo. Isso prejudica a aprendizagem delas (P. 31).

O cenário das aulas de Educação Física representa um espaço onde os corpos são expostos, seja no sentido estético ou de acordo com o desempenho motor, o que faz com que as meninas sejam mais propensas em se incomodarem com os olhares motivados pela sua aparências ou dificuldades motoras (Duarte \& Mourão, 2007; Slater \& Tiggemann, 2011). A imagem corporal é normalmente associada à prática de atividades físicas (Trudeau \& Shephard, 2008) e, na adolescência, as meninas muitas vezes evitam as atividades que as fazem suar e atrapalhar o cabelo, posturas consideradas naturais para elas e que as levam a comparar a sua aparência ao ideal feminino dominante (Abreu, 1995; Klomsten et al., 2005).

A vergonha, que apresenta considerável proximidade com o medo, ocasiona alterações fisiológicas por meio do sistema visceral. Ela gera um desconforto que pode comprometer as relações sociais do indivíduo, além de seu equilíbrio interior. É considerada um sentimento de insegurança ou de uma situação considerada embaraçosa. Manifesta-se quando o indivíduo é observado e julgado, tendo o resultado das ações comparados com comportamentos anteriores ou de outras pessoas (Lavoura \& Machado, 2007).

O presente estudo procurou apresentar uma análise a respeito da participação feminina nas aulas de Educação Física realizadas no município de Volta Redonda/RJ/Brasil, tendo o Basquetebol como conteúdo das mesmas. Todavia, 
esta pesquisa apresenta algumas limitações, a saber, a não autorização da realização da pesquisa por parte de alguns diretores de escolas privadas e a ausência do Basquetebol como conteúdo das aulas de Educação Física no planejamento de alguns professores participantes da pesquisa. Sugere-se a realização de mais estudos com as mesmas características metodológicas que objetivem a devida análise em outros municípios, para que se possa fazer comparações que resultem em uma clara caracterização do Basquetebol praticado por meninas nas aulas de Educação Física em diferentes localidades, o que contribuirá para o desenvolvimento da modalidade no país.

\section{CONCLUSÕES}

Com base nos resultados analisados, percebeu-se que, de acordo com a visão dos professores participantes do estudo, a Educação Física Escolar no município de Volta Redonda apresenta características em que a predominância masculina se faz presente, talvez pela influência do fato de que Esporte é visto invariavelmente como uma prática dominada pelos homens, mesmo a considerar o avanço significativo das mulheres neste cenário. Diante disso, sugere-se que os professores de Educação Física, em prol do alcance de resultados, não estabeleçam comparações de rendimentos entre as meninas e os rapazes, fato que remeteria as discentes a um plano inferior e, consequentemente, transformaria as aulas em práticas desmotivantes.

Percebeu-se que as possibilidades de intervenção pedagógica no decorrer das aulas devem ser privilegiadas por meio do professor de Educação Física. Compete a ele, entre algumas ações, observar que nem todas as meninas são habilidosas para jogarem Basquetebol, fato que não as torna impossibilitadas de participarem das aulas.

Sobre o rendimento das meninas nas aulas de Educação Física, tendo o Basquetebol como conteúdo, notou-se também que, de acordo com os docentes entrevistados, a carência de habilidades representa uma dificuldade quanto ao processo de ensino e aprendizagem da modalidade. Sobre esta questão, mencionou-se a ausência de vivências motoras como responsável pela pouca prática de habilidades por parte das discentes.

Por fim, considerando que a Educação Física pode ser vista como uma aliada importante no alcance de objetivos vinculados à formação de valores, a prática do Basquetebol em ambiente escolar por meninas pode representar, para os alunos, um novo desenho quanto à compreensão de igualdade de direitos e não hierarquização.

\section{Agradecimentos: \\ Nada a declarar}

\section{Conflito de Interesses:}

Nada a declarar.

\section{Financiamento:}

Nada a declarar.

\section{REFERÊNCIAS}

Abreu, N. G. (1995). Análise das percepções de docentes e discentes sobre turmas mistas e separadas por sexo nas aulas de educação física escolar. Em E. Romero (Ed.), Corpo, Mulher e Sociedade (pp. 157-176). Campinas, São Paulo: Papirus.

Balbinotti, M. A. A., Saldanha, R. P., \& Balbinotti, C. A. A. (2009). Dimensões motivacionais de basquetebolistas infanto-juvenis: um estudo segundo o sexo. Motriz, 15(2), 318-329.

Bassani, J. J., Torri, D., \& Vaz, A. F. (2007). Sobre a presença do esporte na escola: paradoxos e ambigüidades. Movimento (ESEF/UFRGS), 9(2), 89-112.

Betti, M., \& Liz, M. T. F. (2003). Educação física escolar: a perspectiva de alunas do ensino fundamental. Motriz, 9(3), 135-142.

Boyle, S. E., Jones, G. L., \& Walters, S. J. (2008). Physical activity among adolescents and barriers to delivering physical education in Cornwall and Lancashire, UK: a qualitative study of heads of PE and heads of schools. BMC Public 
Health, 8, 273. http://doi.org/10.1186/14712458-8-273

Brown, S. E., \& Macdonald, D. (2011). A lost opportunity? Vocational education in physical education. Physical Education and Sport Pedagogy, 16(4), 351-367. http://doi.org/10.1080/17408989.2010.53519 6

Cairney, J., Kwan, M. Y., Velduizen, S., Hay, J., Bray, S. R., \& Faught, B. E. (2012). Gender, perceived competence and the enjoyment of physical education in children: a longitudinal examination. The International Journal of Behavioral Nutrition and Physical Activity, 9, 26. http://doi.org/10.1186/1479-5868-9-26

Cruz, M. M. S., \& Palmeira, F. C. C. (2009). Construção de identidade de gênero da educação física escolar. Motriz, 15(1), 116-131.

Daólio, J. (1995). A construção cultural do corpo feminino ou o risco de transformar meninas em «antas». Em E. Romero (Ed.), Corpo, $m u$ lher e sociedade (pp. 99-108). Campinas, São Paulo: Papirus Editora.

da Silva, J., \& Beltrame, T. S. (2011). Desempenho motor e dificuldades de aprendizagem em escolares com idades entre 7 e 10 anos. Motricidade, $\quad 7(2)$, 57-68. http://doi.org/10.6063/motricidade.7(2).111

Duarte, C. P., \& Mourão, L. (2007). Representações de adolescentes femininas sobre os critérios de seleção utilizados para a participação em aulas mistas de educação física. Movimento, 13(1), 37-56.

Ferreira, R. M., \& Moraes, L. C. de. (2012). Influência da família na primeira fase de desenvolvimento da carreira de nadadores medalhistas olímpicos brasileiros. Motricidade, 8(2), 4251. http://doi.org/10.6063/motricidade.8(2).711

Fotrousi, F., Bagherly, J., \& Ghasemi, A. (2012). The Compensatory Impact of Mini-Basketball Skills on the Progress of Fundamental Movements in Children. Procedia - Social and Behavioral Sciences, 46, 5206-5210. http://doi.org/10.1016/j.sbspro.2012.06.410

Klomsten, A. T., Marsh, H. W., \& Skaalvik, E. M. (2005). Adolescents' Perceptions of Masculine and Feminine Values in Sport and Physical Education: A Study of Gender Differences. Sex Roles, 52(9-10), 625-636. http://doi.org/10.1007/s11199-005-3730-x

Knijnik, J. D. (Ed.). (2010). Gênero e esporte: masculinidades \& feminilidades. Rio de Janeiro: Apicuri.

Kunz, E. (2006). Transformação didático-pedagógica do esporte ( $7^{a}$ ed.). Ijuí, RS: Unijuí.

Lavoura, T. N., \& Machado, A. A. (2007). A vergonha e sua relação com a prática esportiva: um estudo de caso. Motriz, 13(1), 64-71.
Minayo, M. C. de S. (2010). O desafio do conhecimento: pesquisa qualitativa em saude (12 ed.). São Paulo: Hucitec.

Newland, A., Newton, M., Finch, L., Harbke, C. R., \& Podlog, L. (2013). Moderating variables in the relationship between mental toughness and performance in basketball. Journal of Sport and Health Science, 2(3), 184-192. http://doi.org/10.1016/j.jshs.2012.09.002

Rodrigues, H. A., \& Darido, S. C. (2012). Basquetebol na escola: uma proposta didáticopedagógica. Rio de Janeiro: Guanabara Koogan.

Rodrigues, H. de A., \& Darido, S. C. (2011). The textbook in school Physical Education: a vision of teachers. Motriz, 17(1), 48-62. http://doi.org/10.5016/19806574.2011v17n1p48

Sáiz, S. J., Calvo, A. L., \& Godoy, S. J. I. (2009). Development of expertise in spanish elite basketball coaches. International Journal of Sport Sciences, 5(17), 19-32. http://doi.org/10.5232/ricyde2009.017.02

Santos, I. E. dos. (2011). Manual de métodos e técnicas de pesquisa científica. Niterói, Rio de Janeiro: Impetus.

Shen, B. (2014). Outside-school physical activity participation and motivation in physical education. The British Journal of Educational Psychology, 84(Pt 1$), \quad 40-57$. http://doi.org/10.1111/bjep.12004

Silva, J. V. P., Dagostin, K. U. D., \& Nunez, P. R. M. (2009). Educação física e conteúdos trabalhados nas séries iniciais do ensino fundamental. Motriz, 15(3), 592-599.

Silva, R. B., Matias, T. S., Viana, M. da S., \& Andrade, A. (2012). Relação da prática de exercícios físicos e fatores associados às regulações motivacionais de adolescentes brasileiros. Motricidade, $8(2)$, 8-21. http://doi.org/10.6063/motricidade.8(2).708

Slater, A., \& Tiggemann, M. (2011). Gender differences in adolescent sport participation, teasing, self-objectification and body image concerns. Journal of Adolescence, 34(3), 455-463. http://doi.org/10.1016/j.adolescence.2010.06. 007

Souza Júnior, M. B. M., Melo, M. S. T. de, \& Santiago, M. E. (2010). A análise de conteúdo como forma de tratamento dos dados numa pesquisa qualitativa em educação física escolar. Movimento, 16(3), 31-49.

Thomas, J. R., Nelson, J. K., \& Silverman, S. J. (2012). Métodos de pesquisa em atividade física (6. ${ }^{\text {a }}$ ed.). Porto Alegre: Artmed.

Trudeau, F., \& Shephard, R. J. (2008). Physical education, school physical activity, school sports and academic performance. The International Journal of Behavioral Nutrition and Physical Activity, 5, 10. http://doi.org/10.1186/1479-5868-5-10 
Vilhjalmsson, R., \& Kristjansdottir, G. (2003). Gender differences in physical activity in older children and adolescents: the central role of organized sport. Social Science \& Medicine (1982), 56(2), 363-374.
Wu, S.-Y., Pender, N., \& Noureddine, S. (2003). Gender differences in the psychosocial and cognitive correlates of physical activity among Taiwanese adolescents: a structural equation modeling approach. International Journal of Behavioral Medicine, 10(2), 93-105. quando especificado em contrário e nos conteúdos retirados de outras fontes bibliográficas. 